\title{
The Application of Building BIM Information Modeling in Large Domestic Projects
}

\section{Wenke Qin}

Wuhan Polytechnic University, Wuhan, Hubei, 430000

\author{
Keywords: Application, Building BIM Information Modeling, Large Domestic Projects
}

\begin{abstract}
With the rapid development of the computer industry information has become a new trend. Building information modeling (BIM), the latest expression of information technology in the construction industry, is revolutionizing the construction industry. In the increasingly complex situation of modern architecture, the traditional CAD design model can no longer meet the needs of the current construction industry. Therefore, the new collaborative design mode brought by BIM technology has been universally recognized by the majority of designers and has been widely spread all over the world.
\end{abstract}

\section{Introduction}

Influenced by the wave of informationization in the world, the combination of information technology and various industries has become increasingly close. The application of computer technology is also becoming more and more widespread, especially in the construction industry. In the development of the construction industry, architects and engineers have successively experienced the working age of adopting the full manual design, that is, the era of Computer Aided Design (CAD). From the eighties of last century, China's construction industry began to use computer-aided design technology, and through the introduction of the way to the Design Institute and designers to promote CAD graphic design software, and in the subsequent years of learning and reference developed In line with China's national conditions a number of excellent mapping software, structural software and cost software [1]. The late nineties, with the improvement of computer performance, CAD technology began to be rapidly promoted and used. The involvement of CAD software has changed the designer's original way of working, using manual design, design and computational design methods. This not only liberated project designers from the traditional design patterns of manual calculation and manual conversion, but also encouraged each participating project designer to focus more on project design and solution optimization, and significantly reduced the number of designers the workload, improve work efficiency and ensure the overall quality of the project. Therefore, CAD technology represents the first revolution in the domestic construction industry, changing the traditional way of working designers, bringing the construction industry to flourish.

\section{The Related Concepts and Applications of BIM}

At this stage, BIM technology is still an emerging technology, is in a period of continuous development, and its definition is also constantly improving with the development of technology, and because each person on the BIM point of view and application of different ways, the definition of BIM concept and There is no uniform statement. However, the most widely accepted definition of the BIM standard in the United States at present [10]: BIM is a digital model of information that includes the physical and functional aspects of a building, and is a building block that begins with the initial planning stage for the entire The life cycle provides a solid foundation for decision making. The BIM is defined by the ISO Committee on Facilities and Information as a computationally-computable and computational form of the physical and functional characteristics of facilities and their associated project life-cycle information under open industry standards that BIM supports to make decisions In order to better realize the value of the project. Although China's 
BIM standard is being prepared, BIM has been initially defined as a shared digital expression of the physical characteristics, functional characteristics and management elements of the whole life-cycle project or its components in our country. Therefore, BIM can be understood as a way to build a digital model through the establishment of a standard model and a database, which is called the BIM model, and then use the BIM model to plan all stages of the building from scratch, Design, construction, operation and maintenance of building analysis, simulation, optimization design, collision inspection, engineering statistics and post-maintenance process. Narrowly speaking, using 3D digital technology as the foundation of BIM technology, a data model that brings together all the details of a construction project allows all participants to add, extract, modify, and update them in the model. BIM is understood as a way of drawing and designing, or even just a model. In contrast to the broad BIM, the broad BIM is a completely new paradigm that does more than just represent new software or new technologies. The broad BIM is a collection of tools, processes, and methods that result from the goals of building digitization, designing, building visualization, and operational intelligence. Therefore, the narrow sense of BIM is only equivalent to the most basic application. BIM can refer to a digital 3D model of a building that covers a structured data set of shapes and minds called a building information model; it can also be viewed as an activity that establishes the behavior of a building information model, or it can be called Modeling building information. With the development of BIM, there are various versions of the definition of BIM, but this does not affect the vigorous development of BIM because BIM is the integration of building science and IT practice and the only direction for the construction industry to change.

As we all know, technical standards is an industry must comply with the rules for the healthy and stable development of the industry has a decisive role. BIM standards should not simply represent the delivery format of a data model and the naming of components, but should also include provisions for the delivery of content and details between different parties. As the saying goes, "no rules, not a radius," BIM only under the constraints of certain technical standards can give full play to its advantages, the real application to the construction industry. BIM standards are generally broadly divided into two categories of industry standards and national standards. Industry standards are mainly divided into three categories: IFC standards, IDM standards and IFD standards. They are the three major technical bases for realizing the value of BIM. For the release status, refer to Table 2-1. The IFC (Industry Foundation Class) standard is a specification of the file format for the transfer and interoperability of data among the building industries through the industry standard specification BIM model, which is used in the actual project to deliver the basic format of the content. IFC is a standard used to regulate the format of information exchange in which all information about the entire life cycle of a building is to be stored. Therefore, the IFC standard not only needs to ensure the accuracy of data exchange in different software, but also needs to solve the timeliness of information transfer between different phases of a building. However, due to the large variety of BIM softwares, the integrity and coordination of information transmitted among the softwares can not be guaranteed, and the definition of information requirements and the determination of information delivery schemes are lacking. For this purpose, a set of standards to standardize work flow and information requirements [12] is needed, which is the standard of Information Delivery Manual (IDM). The customization of the IDM standard is to standardize the information required for different phases and to map with the IFC standard to ensure IFC implementation [13]. IFD (International Framework for Dictionaries, International Dictionary) standard contains the BIM standard definition of the concept of each identification code in order to eliminate the surprise between different countries and regions, reduce the obstacles between the software information transfer, improve the accuracy of the exchange of information .

\section{BIM Technology in Large-Scale Projects}

According to the "large-scale government building that promotes BIM application in the construction field" launched by the Ministry of Housing and Urban-Rural Development, BIM technology needs to be used in the construction phase. Revit and Tekla software should be used to model and apply the project. (1) Project Features: The project has a large body mass, a combination 
of steel structure and frame structure, and a large span. (2) Management Features: Full Dynamic Management (3) Analysis of Difficult Points: This project has a large scale of construction and adopts large-span arched steel roofing and underground equipment rooms. The mix of competition area and leisure area leads to complicated construction and construction tasks Heavy; more use of factory prefabricated site installation of materials, equipment, etc. virtually increase the difficulty of the construction process management. Taking into account the difficulties in the design and construction of the swimming pool, BIM technology using Revit as a platform and the advantages of BIM technology in the design and construction of large and complex structures are proposed to effectively solve the project's difficulties. Since the project is a hybrid structure of steel and frame structures, considering that Revit is far less used in steel structures than Tekla's, the two different pieces of software are reasonably combined to complete the overall model. Combined with professional analysis software, the rationality of the model analysis, and finally delivered to the construction model used to guide the construction.

In order to reflect the advantages of Revit in the modeling process, a unified BIM rule must be established prior to the use of modeling, including determining the working methods used, project splitting and division of labor, unified family repertoire, and BIM mapping rules. The unified BIM rules help the BIM team complete the modeling process efficiently and in an orderly manner.

Working together in Revit software is generally divided into "work sharing" and "model links" in two ways. Work Sharing is a collection of work in Revit, a way to quickly communicate the design of a designer to other participants, and to allow timely sharing of information. In this work focused designers in the design process can accurately view the design intent of others, will help the program more reasonable. Either way, you can combine multiple models together, but with some of the most fundamental differences. The use of worksets between different disciplines can lead to over-centralization of documents. Therefore, it is mainly used for the coordination among the same professions. "Model Link" is a more technically mature and stable performance of the current collaborative approach, and through the link mode will reduce the computer memory footprint, it is generally used for larger projects between different professional collaboration. This approach is to link a model into a new model is not allowed to modify, you can only re-open the model to be modified. However, the working collaborative method using the Revit link model does not have the convenience of the collaborative working set, the link model can not be automatically updated, and the local files of various professional engineers can not be automatically updated to the server, and the manual updating is cumbersome and can not be guaranteed efficiently The update frequency may not be able to feed back the results of the model modification to other professional engineers. However, with some file synchronization software, the automatic synchronization of automatic updating can be achieved and the same working synergy effect of the Revit working set can be achieved.

\section{Conclusion}

This article introduces the application process of BIM technology in the design institute through practical projects, including the choice of the mode of collaborative design, the establishment of the model, the collision check and the optimization of the drawing. In the initial stage of design, the collaborative working mode of link mode should be selected according to its own conditions and project characteristics, that is, the independent model files should be modeled independently from each other. Connect different professional models into Navsworks software for preliminary crash checking. The result of the collision inspection is returned to the model according to its ID to be modified and optimized. Finally, the optimized model is combined with the domestic standard of the drawing to optimize the construction drawing. Through the application of collision checking technology, common mistakes contained in the design are found in advance, and the errors are corrected and optimized, the error rate in construction drawings is reduced, and the work efficiency in the design stage is effectively improved. This article mainly summarizes and analyzes the operation of the software, and summarizes the problems encountered in the process of using, hoping to provide experience for the application of BIM technology. 


\section{References}

[1] BILAL. SUCCAR, WILLY. SHER. ANTHONY. Williams. Measuring BIM Performance: Five Metrics. Architectural Engineering \& Design Management, 2012, 8(2):120-142.

[2] H. ISHIKAWA. Y. OGATA. K. ADACHI. et al. Building Smart Appliance Integration Middleware on the OSGi Framework. IEEE International Symposium on Object-Oriented Real-Time Distributed Computing, 2004. Proceedings. 2004:139-146.

[3] B. A. BRUCKER, M. P. CASE, E. W. EAST., et al. Building Information Modeling (BIM) A Road Map for Implementation To Support MILCON Transformation and Civil Works Projects within the U.S. Army Corps of Engineers. 2006.

[4] GOLPARVAR. FARD, MANI. SAVARESE, SILVIO. Automated Model-Based Recognition of Progress Using Daily Construction Photographs and IFC-Based 4D Models. Banff, AB, Canada. 2010:51-60.

[5] M. A. HATTAB, F. HAMZEH. Using Social Network Theory and Simulation to Compare Traditional Versus BIM-Lean Practice for Design Error Management. Automation in Construction, 2015, 52(April 2015):59-69.

[6] R. SACKS, E. PIKAS. Building Information Modeling Education for Construction Engineeringand Management. I: Industry Requirements, State of the Art, and Gap Analysis. Journal of Gastroenterology \& He patology, 2013, 139(11):1214-1214(1).

[7] E. PIKAS, R. SACKS. O. HAZZAN. Building Information Modeling Education for Construction Engineering and Management. II: Procedures and Implementation Case Study. Journal of Construction Engineering \& Management, 2013, 139(11):328-330. 